Linguistik Terapan 18 (3) (2021):206-217

Jurnal Linguistik Terapan Pascasarjana

Available online

http://jurnal.unimed.ac.id/2014/index.php/JLT-Unimed

\title{
FACTORS OF SEMANTIC EMOTION OF COVID-19 NEWS AFTER INTRODUCTORY VACCINE ON TWITTER
}

\author{
Friska Pakpahan \\ Anni Holila Pulungan \\ Meisuri
}

\author{
English Applied Linguistics Study Program \\ Postgraduate Program-Universitas Negeri Medan
}

Diterima September; Disetujui Oktober; Dipublikasikan Desember

\begin{abstract}
This study is based on the fact that the readers get words emotion after reading the tweets of covid-19 news. Various emotions found on the tweets of twitter relate to the Covid-19 news. Some of them make the readers being fear or sad of this pandemic. This study deals with semantic emotion of covid-19 news in twitter account of CNN Breaking News. The objectives of the study is to investigate how the semantic emotions realized in Covid-19 news. The study was conducted by using descriptive qualitative. The data of this study were words from tweets which contain semantic emotion of Covid-19 news in twitter. The sources of data in this study were Covid-19 news in twitter, after vaccine Covid-19 distributed since beginning of January 2021. It was found that emotions were realized in covid-19 news, namely: basic emotion, emotional relations, caused emotions, causative, emotional goals, and complex emotions. Contrary with the expectation, happiness was the dominant emotion found in covid-19 news on twitter. Happiness is an emotion to show pleasant, while covid-19 in unpleasant situation. But in this research, it was found that happiness had a high frequency.
\end{abstract}

Keywords: Semantic Emotion, Covid-19, Twitter, Vaccine

How to cite: Pakpahan, Friska (2021). Factors of Semantic Emotion of Covid 19 News after Introductory Vaccine on Twitter. Jurnal Linguistik Terapan Pascasarjana Unimed. 18 (3): 206-217

ISSN: 2407 - 7410

\section{INTRODUCTION}

Language is a classified system of communication, conducted through sounds and symbols. Dong (2014) pointed out that language exists as a symbolic system of abstract thinking and meaning, and it reveals a method and mode of describing the objective world. In 
daily communication, people interact with others in order to understand information or ideas presented in language. Kreidler (1998) says that language is a system of signs that people use to communicate.

People use language for many purposes. People communicate with others about what they know or think, express their feelings, ask questions, make a request, protest, criticize, insult, apologize, promise, thank, say hello, and goodbye. The speakers encode their message and addressees decode them according to their understanding. Sometimes, people use body language to express their intention, while the listener just needs to understand the speaker's expression. In attempting to express themselves people do not only produce utterance containing grammatical structures and words but also they perform actions via those utterances. Lindquist (2017) pointed out that language and emotion are definitely linked. Humans use words to describe how they feel in spoken conversations, when thinking to ourselves, and when expressing ourselves in writing.

People use language to tell others what they know or think. Words used in various contexts change the meaning and evoke different responses in those who hear or read them. Language is a set of words that have meaning. Meaning can be studied through the scientific study of language called linguistics. The branch of linguistics that deals with meaning is called Semantics. In the meaning, there is an emotion that appeared to the reader. The word semantic is derived from the Greek word semaino, which means to express or mean. Semantics is part of a larger study of signs and semiotics. Hipkiss (1995) pointed out that semantics is the processing of words as symbols (symbols) and language as a symbol system (words as symbols).

Semantic emotions can be explained as how we understand feelings in terms of sentences, opinions, circumstances, locations or situations. Emotions are intertwined with the nervous system, affecting opinions, verbal, environment, moods, reactions, and a certain step of pleasant or unpleasant. Emotions are universal and are inseparable from condition, character, temperament, emotion, creativeness, inspiration and temperament. Emotions are also closely related to arguments or verbal. People's emotions can be understood in the words or language they are expressed. Indefinite languages can cause difficulties for everybody who interconnects with the translator or interpreter.

Covid-19 news is spreading widely and can be accessed through the media, whether it is offline newspapers or magazines, or the Internet such as online social media. Social media refers to the interactive way people create, share, and/or exchange information and ideas in virtual communities and networks. Technology continues to reshape our perception of virtual 
public networks, and this review article is arranged out to familiarize, describe, and reflect the use of Twitter. Twitter is a social network stage that allows clusters and persons to break in trace by switching short status posts (140 characters limit). Mistry (2011) and Bristol (2010) believe that Twitter is a broadly used free public networking instrument that lets people to share information in present news feeds by posting short comments about their experiences and thoughts.

In relation to the background of the study, the problem is formulated as the following; how are the semantic emotions realized in Covid-19 news on Twitter? Then the objective of the study is to analyze the realization of emotions in Covid-19 news on Twitter. In this study, researchers investigated the semantic emotion on a tweet that served as Covid-19 news after the vaccine was distributed. This study focuses on semantics emotions in tweets about Covid19 news on Twitter.

The study of word meaning and semantics also helps us to be more discerning in the use of words. The more we understand the usage of words, the more we can distinguish their usage, the more refined our thinking, because the concepts conveyed by words become more accurate, more relevant, and more useful in analysis. Semantic analysis of English words involving emotions. Johnson-Laird, P., \& Oatley K., (2000) assume that emotion has a dual communication function, which is not only an external communication function between species members, but also an internal communication function in the brain, which can avoid multifarious reasoning. It implies that there are a few basic signs in the organism that can establish typical emotional modes, which roughly correspond to happiness, sadness, fear, anger, and disgust. In socials, these patterns can be adjusted by the propositional content that causes the cognitive evaluation of emotional signals.

Emotional words should also express different interpretations of basic emotional patterns. Johnson-Laird \& Oatley (2000) pointed out that emotions function as dual communication, which can produce a series of behaviors on the evidence handling system and the communication system within organisms with minimal load. They divided the words that express emotions into six categories based on semantic classification. They can represent:

\section{Basic Emotion}

Our theory assumes five basic emotion modes, so we can expect that there should be words that openly refer to these emotions or just modify them. Therefore, these words ought to represent emotions that can be practiced without the experiencer deliberate the reason, although they can also be used to state emotions practiced for a recognized reason. 
How do we decide that a word is semantically connected to one of the five modes of "happiness", "sadness", "fear", "anger" and "disgust". One technique is to use the so-called "but" test (Bendix, 1966; Miller \& Johnson-Laird, 1976). If two words have not anything in mutual, they and their negative words can be easily joint with the conjunction "but". For instance; he is weary, but he is happy, he is weary, but he is not happy.

The "but" test assistances to tell the modification of the basic pattern, including the strength of the pattern. Therefore, "happiness" means feeling quite happy, and "ecstatic" means feeling strong happiness. Generally speaking, the stronger the emotion, the harder it is to experience, because the extreme emotions close to pathology are felt without meaningful motive. However, it expresses that basic emotions such as happiness, irritability, or freefloating anxiety can be strongly experienced for no reason. There are 109 words in the corpus to express basic emotions as can be seen on Table 1 .

Table 1. A sample of words denoting basic emotions

\begin{tabular}{lllll}
\hline \multicolumn{5}{c}{ Basic Emotion Modes } \\
\hline Happiness & Sadness & Fear & Anger & Disgust \\
light-hearted & wistful & timid & grouchy & \\
carefree & gloomy & tense & touchy & queasy \\
happy & sad & anxious & irritable & nausea \\
high & melancholic & fearful & angry & \\
euphoric & depressed & panicky & irascible & \\
ecstatic & wretched & craven & splenetic & \\
\hline
\end{tabular}

2. Emotional Relations

Emotions are usually about someone or something; they are more possibly to be practiced persons or their movements than just being in a vacuum. Therefore, one should suppose some words to denote the relationship concerning the person experiencing the emotion and the object, such as "James is afraid of Jean."

Fear and anger can have the object's thoughts without any problems. Love and hate must also have substances, and our concept suggests that they also rest on the mixture of emotional modes happiness and disgust, respectively and the recognition of the individual or person who recognizes who or which emotion is feeling. The cause of this emotion can be regarded as its cause, but there are some delicacies that need to be addressed. People can practice feelings for somebody without thoughtful why they feel that way. Therefore, just as a 
person can be happy for no reason, a person can love, hate, or anxiety someone without deliberate the purpose. As academics, we do uncertainty the reason for this emotion, but the reason may have tiny or nothing to organize with the purpose of the emotion, and might not enter the awareness of the individual feeling the emotion.

Hate is usually spoken in an angry way, but this construction is accidental, not necessary: you can hate somebody or something without feeling angry; you can be angry with somebody you don't hate. Grief can also need objects, such as when you miss somebody who is separated from you. Compassion and compassion rest on the same emotional modes, but they are the multipart emotions we will face now. There are 76 words in the corpus to express emotional relationships.

Table 2. A sample of words denoting emotional relations

\begin{tabular}{lllll}
\hline \multicolumn{4}{c}{ Basic Emotion Modes } \\
\hline Happiness & Sadness & Fear & Anger & Disgust \\
Like & miss & afraid of & aggrieved with & dislike \\
love & mourn & Fear & angry with & hate \\
adore & grieve for & dread & scorn & loathe \\
\hline
\end{tabular}

\section{Caused Emotions}

Definite words that express emotions usually express a feeling, and the reason for this feeling is recognized to the individual feeling it. For example, if you say "I am happy", then, as the "but" test shows, you will be happy, but you cannot correctly deny all knowledge that causes this situation.

Therefore, we can adjust the "but" test to the second clause: "but I don't know why" or "but I know why". Tests have shown that words related to basic emotions (see, for example, Table 2.2) do not essentially cover reasoning components. For example, it is impeccably wise to state that I am happy but I don't know why or I am happy but I know why. However, the claim is weird: I am happy, but I don't know why, because the term is usually used to associate emotion with cause or cause, such as "I am happy because winter has passed", or to definite an attitude towards a proposition such as "I'm glad that winter has passed." Therefore, the language makes the difference that our philosophy predicts: some emotions are practiced without deliberate the source or motive, while other emotions we call emotions that trigger emotions are based on experienced after knowing the purpose. Of course, all emotions have a reason, so our labels only imply that the experiencer knows certain aspects of it. The 
five basic emotion modes should also be the basis for triggering emotions, and this prediction is confirmed by analyzing the terms involved in triggering emotions.

Table 3. A sample of words denoting caused emotions

\begin{tabular}{lllll}
\hline \multicolumn{4}{c}{ Basic Emotion Modes } \\
\hline Happiness & Sadness & Fear & Anger & Disgust \\
cheered & dejection & apprehension & disgruntled & \\
enjoyment & sorrow & consternation & miffed & \\
glad & heart-broken & Afraid & indignant & disgust \\
delight & inconsolable & Panic & cross & sick \\
\hline
\end{tabular}

\section{Causative}

There are 101 words in our corpus that can be used to express the emotions affected. A mutual system of discourse that causes emotions depends on causal verbs. As we have already noticed, these verbs definite the relationship between the reason of the emotion and the individual experiencing it, such as "this news has annoyed the president." Therefore, the passive form of the verb can be used to state the emotion aroused: "The president is annoyed by the news." Generally speaking, the explanation of the cause of emotion is the opposite of the explanation of the cause of emotion. Some verbs indicate the cause of each of the five main emotional patterns. There are 180 words in our corpus that can be used as causes.

Table 4. A sample of words denoting causative

\begin{tabular}{lllll}
\hline \multicolumn{5}{c}{ Basic Emotion Modes } \\
\hline Happiness & Sadness & Fear & Anger & Disgust \\
content & deflate & disquiet & irk & put off \\
please & disillusion & perturb & peeve & alienate \\
amuse & dampen & worry & irritate & estrange \\
delight & depress & scare & annoy & repel \\
transport & sadden & frighten & enrage & nauseate \\
enthrall & disappoint & terrify & incense & sicken \\
exhilarate & desolate & Petrify & infuriate & revolt \\
\hline
\end{tabular}




\section{Emotional Goals}

Emotions are often used as motivations, leading to characteristic behaviors aimed at achieving goals. Love leads to approaching grief leading to withdrawal and indecision, fear leads to avoidance, anger leads to attack, and hate leads to evasion. Achieving goals will produce happiness, and definite words indicate the state of having goals (such as inclinations, desires, needs, desires). Other terms refer to specific types of goals (e.g. interest, greed, desire). Unachieved goals may lead to sadness or anger. Some words indicate these situations (for example, dissatisfaction, displeasure, hindrance). There are other verbs that can definite sadness caused by frustration in love or desire (for example, longing, longing, lovesickness). 42 words represent the emotional targets in our corpus.

\section{Complex Emotions}

Express basic emotions of the word can also be used to refer to complex emotions. Therefore, someone can say: "I feel worried because I know I made a fool of myself in front of those persons", then decide that this situation is a kind of awkwardness, which is a slight fear or shame, carried about by sensible evaluation of oneself in social situations. Since expressions referring to basic emotions can also be used to refer to complex emotions, the construction of language cannot be tangled with the fundamental construction of emotions. The words in Table 2.7 can state the basic emotions and complex emotions.

Given our analysis, this option is predictable because we claim that all complex emotions depend on basic emotional patterns. If a particular complex emotion appears commonly in principles and may have a special meaning in public relations, then, just like in other discourse fields, suitable relations may be used to refer to it in language. The theory therefore denotes that a word that definitely expresses complex emotions would be able to be analyzed based on basic emotions and other concepts related to the self-model. We have checked this prediction on our corpus, and 81 words represent complex emotions.

Table 5. A sample of words denoting complex emotions

\begin{tabular}{lllll}
\hline \multicolumn{4}{c}{ Basic Emotion Modes } \\
\hline \multicolumn{1}{c}{ Happiness } & \multicolumn{1}{c}{ Sadness } & Fear & Anger & \multicolumn{1}{c}{ Disgust } \\
hope & hopelessness & & & $\begin{array}{l}\text { self-disgust } \\
\text { shame } \\
\text { complacent } \\
\text { despair }\end{array}$ \\
pride & remorse & & self-hatred \\
conceit & self-pity & & \\
closeness & sorry for & shy & bitter & resentment \\
intimacy & sympathy & self-conscious & & envy \\
belonging & bity & embarrassment & jealous \\
\hline
\end{tabular}


Johnson-Laird \& Oatley (1987) believe that only some emotional terms have semantic analysis. They said that by analyzing emotional words and searching for semantic primitives, our discovery of emotion itself is limited. They also claim that once persons talk about emotions in English, they usually correctly state completely different emotional understandings with causes and objects. For instance, when an utterer states to be afraid, the word "afraid" refers to a emotional state with a distinguishing remarkable tone, just as the word "hungry", "sleepy", "in pain" refer to phenomenally distinctive conditions. The utterer is probably to know the cause of the understanding, and the emotion is probably to be focused towards something or someone.

Particular words mean basic emotions, conforming to the modes that can be practiced without consciousness of evaluations on which they are grounded. Other words denote emotions that contain propositional information about a cause or purpose of the emotion, and other words denote complex emotions developing from evaluations of the nature. JohnsonLaird \& Oatley report an analysis of 590 words in English words that we might find to represent emotions.

\section{METHODOLOGY}

This study will explain the semantic sentiment of Covid-19 news on Twitter by applying qualitative design text analysis. Bogdan and Biklen (1992) described that qualitative is descriptive, where data is in the form of text or pictures rather than numbers. In addition, Denzin and Lincoln (2000) pointed out that qualitative research involves explanatory and naturalistic methods. The type of research is content analysis. Ary (2010) pointed out that content or document analysis is a research method applied to written or visual materials to identify specific characteristics of materials. The data of this study are words from tweets that contain semantic emotion of Covid-19 news on Twitter. The sources of data in this study are Covid-19 news twitter, after vaccine Covid-19 distributed since the beginning of January 2021. The data to be analyzed will be taken from the beginning of January 2021 up to the end of March 2021. The technique of data collection is applying the documentary technique. Burhan (2007) states that the documentary technique is a method for collecting the data which is kept in the form of documentation. Then, technique of analyzing data used theory of Miles, Huberman, and Saldana (2014) with their steps for analyzing data, they are (1) data collection, (2) data condensation, (3) data display, (4) data verification/conclusion. 


\section{FINDINGS AND DISCUSSIONS}

Six realizations of emotion occurred in covid-19 news on Twitter. All of them were found here in this research. The result of those realizations could be seen in the following. The table below would give the sample of the realization of emotion in covid-19 news on Twitter were found in the data. There were 6 the process of realizations of emotions in covid19 news on Twitter. They can be seen in the Table 6 .

Table 6. The Percentages of Realizations of Emotions

\begin{tabular}{llcc}
\hline NO & \multicolumn{1}{c}{ Realizations } & Total & Percentages (\%) \\
\hline 1 & Caused Emotions & 14 & 38.89 \\
2 & Emotional Relations & 9 & 25.00 \\
3 & Causative & 6 & 16.67 \\
4 & Complex Emotions & 4 & 11.11 \\
5 & Emotional Goals & 2 & 5.56 \\
6 & Basic Emotions & 1 & 2.77 \\
& Total & 36 & 100.00 \\
\hline
\end{tabular}

From Table 6, we can see the realization process of emotion in covid-19 news on Twitter. Six realizations were found, namely: 1) basic emotion, 2) emotional relationship, 3) induced emotion, 4) cause and effect, 5) emotional goal, 6) Complex emotions. Futhremore, the researcher found $14(38.89 \%)$ caused emotions as the process realization of emotion in covid-19 news on Twitter. It could be concluded that caused emotions had high frequency in the process of realizing emotions. It happened because the main term here is Covid-19 as a pandemic that we have today, and it's the main reason or the main cause to be related to causing the emotion on tweets. Caused emotion is the term that is generally used to tell emotion to a purpose or source. It means that emotions generally appear caused by a reason or a cause. The next process of realization of emotion in covid-19 news is basic emotions as the lowest frequency of semantic emotion. It was found $1(2.77 \%)$ basic emotions as the process of realizing emotions on tweets about covid-19 news. It happened because nearly all the tweets or news which has emotional's words in the statements have the reason or the cause that is the covid-19 cases. Basic emotions refer to emotions that can be practiced without the experiencer deliberate the reason. Basic emotions can be practiced strongly for no intention. In this study, the researchers found that the tweet or statement has its main reason or reason, that is, we are today as a global pandemic case of covid-19. On the other hand, for the other process of realizing emotion, it can be found that there were 9 (25.00\%) emotional 
relations, causative was $6(16.67 \%)$, emotional goals were $2(5.56 \%)$, and complex emotions was $4(11.11 \%)$ as the process of realizing emotions in covid-19 news on the Twitter account of CNN Breaking News.

\section{Basic Emotions}

After analyzing the data, only one basic emotion was found in CNN breaking news tweets. This means that words or tweets about covid-19 news represent emotions that can be practiced without the experiencer expressive the source, although they can also be used to refer to emotions practiced for an identified cause. Basic emotions can be experienced strongly for no reason. According to Johnson-Laird \& Oatley (2000) corpus or sentiment words, there are 109 emotional words that realize basic emotions.

\section{Emotional Relations}

On the Twitter account of CNN Breaking News, 9 (25\%) emotional relationships were found in the data as a process to realize emotions in covid-19 news. Emotions are usually about someone or something; they are more likely to have experience with the person or their behavior, not just in a vacuum. Therefore, people should expect some words to refer to the relationship between the person experiencing the emotion and the object. According to Johnson-Laird \& Oatley (2000) corpus or emotional words, there are 76 emotional words that realize emotional relationships

\section{Caused Emotions}

Inducing emotion is the process of finding emotion in data. There are 14 (38.89\%) processes that trigger emotions in the data. Certain words expressing emotions usually express a feeling, and the reason for this feeling is known to the individual experiencing it. Obviously, all emotions have a reason, so our labels only imply that the experiencer knows certain aspects of it. According to Johnson-Laird \& Oatley (2000) corpus or emotion words, there are 101 emotion realization words in the emotion caused.

\section{Causative}

Through the analysis of the data, the researchers found 6 (16.67\%) causal processes to realize emotions. A common form of discourse that causes emotions depends on causal verbs. As we have already noticed, these verbs definite the relationship concerning the source of the emotion and the individual experiencing it. There are 180 emotional words in the corpus that can be used as causes.. 


\section{Emotional Goals}

Only $2(5.56 \%)$ of the emotional goal process is to achieve emotion. Emotions are often used as motivations, leading to characteristic behaviors aimed at achieving goals. Achieving goals will produce happiness, and certain words indicate a state of goal. Unachieved goals may lead to sadness or anger. There are 42 emotion realization words in the emotion goal in the corpus.

\section{Complex Emotions}

Four complex emotion realization processes $(11.11 \%)$ were found in the data. Arguments that express basic emotions can also be used to refer to complex emotions. The theory therefore implies that words that specifically express complex emotions should be able to be analyzed based on basic emotions and other concepts about the self-model, which collectively correspond to the propositional content of experience. According to JohnsonLaird \& Oatley (2000) corpus or emotion words, there are 81 words dealing with complex emotions.

\section{CONCLUSIONS}

This study focused on the semantic emotion of covid-19 news on the Twitter account of CNN Breaking News. It was aimed to find out the types of emotions in covid-19 news on Twitter, then to find out how they were realized in the process of realizing emotions and the last was to explain the reason why the emotions were realized in covid-19 news on Twitter. After analyzing the data, the conclusions can be drawn as the following: Emotions were realized in covid-19 news on Twitter through 6 categories, namely: 1) basic emotions, 2) emotional relations, 3) caused emotions, 4) causative, 5) emotional goals, and 6) complex emotions. Caused emotions hada high percentage realized in covid-19 news on Twitter and the lowest was basic emotions. All categories were realized in tweets of covid-19 news. It happened because the main term here is Covid-19 as a pandemic that we have today, and it's the main reason or the main cause to be related to causing the emotion on tweets. Caused emotion is the term that is normally used to relate emotion to a reason or cause. It means that emotions generally appear caused by a reason or a cause. 


\section{REFERENCES}

Bogdan, R. C. and S. K. Biklen, (2007). Qualitative Research for Education:An Introduction to Theory and Methods. $5^{\text {th }}$ Edition, Allyn \& Bacon, Boston.

Hipkiss, R. A. (1995). Semantic Defining The Discipline. Lawrence Erlbaum Associates, Publisher. New Jersey

Lindquist, K. A. (2017). The Role of Language in Emotion: Existing Evidence and Future Directions. Current Opinion in Psychology, Volume 17, Pages 135-139.

Johnson-Laird, P. and K. Oatley, (2008). Basic Emotions, Rationality, and Folk Theory. Cognition and Emotion, 1992, 6 (3/4), 201-223. : http://www.tandfonline.com/page/terms-and-conditions.

Johnson-Laird, P. and K. Oatley, (2008). The Language of Emotions: An Analysis of a Semantic Field. http://www.tandfonline.com/page/terms-and-conditions

Oatley, K., and P. Johnson-Laird, (2008). Semantic Primitives for Emotions: A Reply to Ortony and Clore. http://www.tandfonline.com/page/terms-and-conditions. 